\title{
The Influence of Shale Gas Revolution on Global Political and Economic Structure
}

\author{
Liu Junli \\ Macau University of Science and Technology \\ Macau, China
}

\begin{abstract}
The substantial increase in shale gas production of the United States not only has a huge impact on the US energy system, but also changes the political and economic structure of the world. So we call it a revolution. This essay tries to express what has shale gas changed and the possibilities that shale gas revolution will change on different aspects in the world. Through the large-scale development of shale gas in the United States, it also provides new ideas to other countries on energy development. The United States should take advantage of the opportunity to achieve energy independence, seek possible energy exports, increase imports of foreign sources of oil and gas and resource acquisition efforts to maximize their own interests in the new round of adjustment in international relations, enhance their influence on global affairs.
\end{abstract}

Keywords—shale gas; revolution; United States

\section{INTRODUCTION}

As is well known, shale gas revolution will have a huge economic impact on global politics. Development of US shale gas industry is the occurrence of a series of policies to promote world technological progress, but it still depends on the United States mostly thorough protection of property rights and free competition market structure.

Shale gas revolution has changed the global oil and gas market. It accelerates the global oil and gas production center westward and consumer centers eastward trend. Competition in the global oil and gas market will become increasingly fierce. World natural gas market will usher in a new period of development. Strengthen the dominant global currency role of the dollar. Shale gas revolution has a "non-neutral" impact on the global economy. It reduces the cost of the United States "re-industrialization", accelerating the recovery process of the US economy. Also, Promote US energy exports and reduce the trade deficit. For the development of China's shale gas industry provides a good reference, but it also brings the potential impact. Shale gas revolution makes leveraging geopolitical plates changed. US strategic contraction in the Middle East will cause a chain reaction. The relationship between the major powers will show a new pattern. Global response to climate change will usher in a new development. Sino-US relations will be presented as energy cooperation and new features.

\section{CONTENT}

In recent years, a series of major changes in the US shale gas occurs, is known as shale gas revolution, not only because of the massive increase of US shale gas production. It is not only because of the impact produces limited to the United States, but also to overturn the unconventional oil and gas resources will only complement the conventional fossil fuels, the traditional understanding, in turn, it will affect the pattern of world energy, geopolitics and the global economic order. As a clean and efficient energy, the size of shale gas for America's energy supply and energy alternatives provide a new perspective, but also provides a new way for the development of other countries in the oil and gas industry. Our concern is that the shale gas revolution will affect the world situation?

\section{A. The shale gas affects the world's situation}

Firstly, as a resource and shale gas industry, shale gas refers to occur in organic-rich mudstone or shale and laminated in the form of adsorption or free inside presence in shale gas resources. When appropriate external conditions occur in the organic shale and liquid hydrocarbons have been generated after cleavage or degradation of the formation of gaseous hydrocarbons, or free from pores and cracks, or adsorbed on the surface of organic matter and clay minerals, and certain geological conditions by gathering form shale gas reservoirs. Different from conventional gas reservoirs, shale gas production of both shale source rocks is shale gas accumulation and storage reservoirs, such as self-generation and self-storage feature determine the occurrence of shale gas environment lower natural pressure, poor porosity and permeability, mining difficult, technically demanding, and therefore belong to unconventional shale oil and gas resources. Among them, the most abundant shale gas resources in North America, accounting for 29.2 percent of the global total; the Asia-Pacific region of technically recoverable shale gas resources amounted to 50.52 trillion cubic meters, accounting for 27.0 percent of the global total. From the national point of view, China's shale gas resources in the world, with the United States, Argentina, Mexico, Australia and Canada together as technically recoverable shale gas resources of over 10 trillion cubic meters in five countries. Currently, there are over 30 countries are conducting shale gas exploration and development, but in general the world's shale gas industry is still in its early stages, in addition to the United States and a few other countries have made substantial breakthroughs beyond, most countries still progress more slowly.

US shale gas production has a long history. As early as 1821, the United States succeed in the Appalachian Basin shale 
gas wells to drill the first port business, opened a prelude to shale gas, they opened the US natural gas industry. In the 1970 s, due to the arrival of the two oil crises and domestic crude oil production peaks, the proportion of natural gas in the United States energy consumption structure, increasing push into the large-scale exploitation of shale gas phase, production reached 2 billion cubic meters, but proportion of the total natural gas production is still small. Until the 1990s, technological breakthroughs as well as various aspects of system infrastructure continues to improve, it has brought prosperity shale gas industry. US shale gas production in 2001 was 12.6 billion cubic meters, accounting for only 2.3 percent of natural gas output; to 2011 has reached 182 billion cubic meters, accounting for the proportion of total gas production $27.9 \%$ average annual growth rate of nearly 10 years more than $25 \%$. The rapid rise in shale gas production, reversing the decline in US natural gas production in the situation, and push the United States back in 2009 over Russia, once again become the world's largest gas producing country. According to EIA forecasts, the future of US shale gas production will continue to maintain the trend of rapid growth in 2020 to reach 250 billion cubic meters, accounting for $36 \%$ of gas production; in 2030 reached 380 billion cubic meters, accounting for $49 \%$ of the total gas production.

With American's influence, Canada became the world second achieve commercial exploitation of shale gas country. Canadian shale gas resources are relatively abundant, technically recoverable resources reached 10.98 trillion cubic meters, ranking fifth in the world, currently shale gas production has been more than 8 billion cubic meters, in addition to achieving self-sufficiency also increased outside Europe and Asia supply area. European shale gas resource-rich, but more dispersed. Exploration mainly in Poland, Germany, Austria, Hungary and other countries, a number of exploration blocks have started commercial production. But because many European populations, environmental constraints more stringent commercial exploitation will take time. Argentine shale gas technology recoverable resources in South America ranks third in the world, it is considered the most countries outside North America, in addition to shale gas development prospects.

Secondly, why shale gas revolution happened? US outbreak of shale gas revolution is not by chance, there are several aspects of the following factors. From a resource perspective, the United States 48 states widely distributed organic shale's, rich in shale gas resources, which is shale gas revolution resource basement. Global shale gas initial evaluation shows that the US shale gas technically recoverable resources amount to 24.4 trillion cubic meters, ranking second in the world. In addition, the US shale gas basins are concentrated, mainly in the eastern and south-eastern and better storage conditions, mining is relatively easy.

From a technical perspective, in 1981, America's first shale gas well fracturing success; in 2002, horizontal drilling is used to increase production of shale gas wells. It is precisely because of the fracturing and horizontal well mastered these two key technologies, the United States effectively reduces the cost of shale gas development, the success of shale gas production to achieve a breakthrough. Shale gas technology has been named one of the top ten scientific and technological progresses in the world's oil in 2009.

From a market perspective, one US natural gas infrastructure is perfect. The United States has the world largest and most comprehensive natural gas pipeline system, pipeline mileage of more than 40 million kilometers, ranking first in the world, developed the contact line between the pipeline, city gas distribution network is perfect, the natural gas pipeline across the state. Improve infrastructure to reduce costs, and promote rapid shale gas market, commercialization has created favorable conditions. Besides, the US energy market environment is very sound. In the previous restructuring of the natural gas market, the US government has always followed the single function pipeline companies, pipeline competition in the market of ideas, through "controlling the intermediate, open at both ends," the establishment of a pipeline open market access system to ensure that the gas production Suppliers and equitable use of natural gas pipelines, improve market efficiency, and ensure the reasonable value reflects the shale gas. America's highly competitive energy market structure, most of the shale gas exploitation by SMEs to effectively disperse the huge investment, reducing the exploitation of barriers to entry, at the same time, small and medium enterprises in order to obtain higher returns, more innovative conduct, which can promote the rapid development of shale gas industry.

From a policy perspective, the US government has long attached great importance to the exploitation of unconventional oil and gas resources. Early in the 1970s, the US government through the Energy unexpected profit Law, Natural Gas Policy Act, and so on shale gas implement tax breaks and subsidies, and has long been insisting the implementation of the shale gas exploitation preferential policies. In addition to the federal government, the rich shale gas resources in local government also introduced a number of incentives, such as Texas, since the early 1990s on the development of shale gas does not levy taxes on production. Meanwhile, the US government has also set up a special research fund unconventional oil and gas resources, such as the 1970s of the "Eastern shale gas project." Since the 1980s, the US government has already invested a total of more than 6 billion US dollars of funds for the shale gas industry; some of the core technology breakthrough is derived from this. In addition, the US government is very concerned about shale gas environmental pollution through the development of appropriate environmental legislation to ensure the coordinated development of US shale gas industry and the environment.

From the perspective of the economic environment, the international oil prices in the 21 century, especially after 2003 into a new round of rising channel, so that shale gas has become technically feasible; the second is long-term low interest rate policy makes the United States the cost of borrowing becomes low, be inspired by the enthusiasm for investment in the event of a network of economic bubble, only to find a new direction of investment, shale gas ultimately be the most appropriate choice. 
But generally speaking, the world's shale gas industry uneven situation will persist; the United States happened shale gas revolution experience is not necessarily applicable to other countries. Firstly, the world shale gas occurrence conditions differ greatly, in line with the US Geological knowledge accumulation is not necessarily applicable to other countries, mining technology is applicable in the United States it is difficult to completely copy to other countries. Secondly, the world is a big gap between the institutional environment, the United States a clear system of property rights is an important incentive to promote shale gas production, while other countries in the short term is difficult or impossible to establish such a property rights system, in addition, other countries also lack sound natural gas pipeline system and equitable market environment. Thirdly, there is a big gap between the countries in the world technical level, the US technology export as an important means to acquire various interests, but treated differently in different countries, some countries it is difficult to obtain US shale gas core technology support. In addition, countries shale gas liquefaction, output, gasification and other key technologies are not the same master. Fourthly, there is a big gap between the countries of environmental policy, hydraulic fracturing shale gas used not only consume a lot of water, exacerbating water stress, and underground injection lysates likely to contaminate groundwater and soil; a lot of water to shale it may also lead to the formation slide, trigger earthquakes. Although the United States has done a lot of conservation efforts, but shale gas in the United States still being environmentalists questioned. In view of this, the environmental pressure greater country, shale gas will encounter greater resistance.

The United States itself, in addition to environmental pressures, the development of shale gas industry also suffered a number of other issues. Since a large number of shale gas development, external pipeline networks and gas storage tank construction due to the long-term natural gas prices decline and become uneconomic, leading oil and gas producers, only the excess shale gas flared, which not only caused a lot of energy waste while also increasing greenhouse gas emissions. Indeed, the United States can be cheap shale gas exports to the rest of the world to solve this problem, but it takes time, but also need the overall plan of the US government. It also provided an excellent reference for other countries in the global economic downturn, weak demand for oil and gas background of the times to develop shale gas industry.

Thirdly, how does the shale gas revolution affect the global pattern? Shale gas revolution substantial increase US energy self-sufficiency, boosting the US achieve "energy independence" dream, but also on the world political economy has had a profound impact.

\section{B. Shale gas revolution changes the global oil and gas market}

One is to accelerate the global oil and gas production center shifted westward, eastward trend of consumer centers. Conventional oil and gas production centers concentrated in the Eastern Hemisphere Russia, the Middle East, West Africa area, but with the recent rise of the US shale gas, Canadian oil sands, Venezuelan heavy oil, Brazil's subsalt oil, the Western
Hemisphere has gradually become the world's oil and gas supplies to another pole. In the US oil and gas imports decreased and with China, India, represented by the rapid rise in consumption of oil and gas country in the East of the dual role of the world's oil and gas consumption trend more apparent eastward flow.

The global oil and gas market competition will become increasingly fierce. The United States long-term low-cost natural gas and gas resources have a strong competitive advantage in the international market. If the United States to achieve natural gas exports, it will squeeze the traditional oil and gas production target market countries, competition between different sources of natural gas, as well as to have a more abundant supply of natural gas in the world market increased by more air supply, causing some to high signed the presence of natural gas supply contract breach risk. However, this is good news for the oil and gas consuming countries, the oil and gas consuming countries to increase oil and gas import sources, reducing the import risk. Meanwhile, the traditional oil-producing countries due to competitive pressure from US oil and gas, and will actively seek potential buyers resources, it will be easier to cooperate, which overseas oil and gas consuming countries will be more favorable access to resources.

Besides, the world gas market will usher in a new period of development. Currently, the global crude oil production remained at around 3.9 billion tons; coal cannot meet the need to address climate change, with a new round of "nuclear panic", natural gas has become a human pursuit of clean development inevitable choice. US shale gas exports will promote the development and utilization of natural gas resources in the world, but also make people pay more attention to the role of unconventional oil and gas resources.

It is to strengthen the world's leading currency role of the dollar. Dollar-denominated oil has become an important part of the dollar hegemony, although some oil-producing countries suffer a lot, but to create the conditions for the global oil market. Regional gas market in the world is more obvious, mainly in North America, Europe and Asia three markets, pricing for each market varies. With the increasingly important role of natural gas and increasingly active trading, global gas market convergence is likely. For now, the dollar is still the most likely denominated in the currency; dollar hegemony will become more stable.

\section{Impact on the United States}

Firstly, it reduces the United States' re-industrialization "of the cost and accelerates the recovery process of the US economy. In the world economic recovery prospects uncertain backdrop, shale gas provides for the re-distribution of the world oil and gas industry opportunity, but also greatly reduces the cost of US implementation of the "re-industrialization" strategy, stimulating the growth of the US economy. Under the guidance of 3D printing technology, robotics, artificial intelligence and other technologies, the US economy may be earlier than the other developed economies lead into recovery and prosperity cycle, become a driving round growth of the world economy important engine. 
The second is to promote US energy exports and reduce the trade deficit. Due to the size of shale gas alternative, the United States can export other energy products in the context of security of energy supply. If the United States began to export shale gas, the oil and gas exports would reduce the US trade deficit, improvement in the US trade environment, and global trade patterns. Long-term trend of the dollar index negative correlation between trade deficits, in conjunction with other factors, the future of the dollar index will likely get strong support, the dollar return to strong era. Lower raw material prices in general in favor of the global economic recovery, while growth in the size of international trade of natural gas is in a sluggish period for the global shipping industry, it may be good news.

Thirdly, a stronger dollar will continue to weigh on commodity prices over the medium term, especially oil and gas prices. The vast majority of conventional oil and gas producing countries in the Middle East in particular, are not to rely on oil and gas industry to establish their true industrial system, but rely on exports of oil and gas resources in exchange for petrodollars to maintain economic stability and growth in the face of competition as well as US oil and gas exports US dollar price index for oil and gas pressure, its economic development will be affected. As the "Jasmine Revolution" is not casual warmth, Syria, Egypt and other countries political situation is still in turmoil, political pressures faced by the Middle East countries thus will persist.

The fourth is that the development of China's shale gas industry provides a good reference, but it also brings the potential impact. After the United States, shale gas revolution broke out; many countries in the world have wanted to copy the American miracle. Our oil and gas supply and demand contradiction, large-scale oil and gas market, abundant shale gas resources, it is considered the countries except North America last possible large-scale development of shale gas industry. The research on the shale gas can be traced back to the 1960s. In recent years, as the country's natural gas industry to accelerate the development of shale gas again, it is taken seriously.

The US strategic contraction in the Middle East will cause a chain reaction. All along, the dependence on Middle East oil and gas is an important reason for the United States to maintain stability in the region, but also to the United States paid a high price, foreign wars and foreign troops have been brought to the United States serious financial pressures and human losses. In the context of the global financial crisis, the dimension following the huge military spending to make the United States feel the pressure. Despite the end of 2012 the US bipartisan "fiscal cliff" to reach a compromise, but the deficit, the debt has become a problem cannot be ignored. Since shale gas revolution reduced dependence on foreign oil and gas, the importance of overseas oil and gas weakened, the United States may implement the necessary strategic contraction from the Middle East, North Africa and other original sources of imports of oil and gas region, or reduce focus on these areas, management, thereby saving military spending, to reduce the financial pressure. America always play a "world policeman" behavior has long been unpopular, but we have to admit that if the United States does not maintain power, the possibility of these oil-producing region will remain stable greatly reduced ability to stabilize oil supply will be greatly reduced. Once the United States from these regions to implement strategic contraction, left to the pattern of how to develop, can continue to maintain stable power vacuum will be how to make up, not only related to the fate of the future of these countries, but also for those dependent on oil and gas consuming countries, especially important to China, India and other countries. World oil and gas geopolitics by the US energy independence profound impact is likely to have unexpected variables. China requires early planning, the use of this important opportunity to fill some of the oil from the US strategic contraction of power left blank, to deepen cooperation with the traditional oil-producing countries to maintain a stable source of supply, to expand its influence on regional affairs and global affairs force.

The relationship between the major powers will show a new pattern. They will tend more and more cooperation between the United States and the oil and gas consumer. US oil and gas exports and gas consumer countries to increase the sources of imports, the import risk dispersion. Western European countries can reduce their dependence on expensive Russian gas; China, India, the big developing countries can also import and export LNG to explore with the United States, the world's major economies, with the US economy more closely. Oil and gas exports to the United States will undoubtedly add to the constraints of the traditional oil and gas producing countries, another weapon. Therefore, the interests of the US relationship between the traditional oil and gas producing countries are likely to occur between the gradual rebalancing. Meanwhile, the traditional oil-producing countries due to competitive pressure from US oil and gas, and will actively seek potential buyers' resources, it will be easier to cooperate on oil and gas consuming countries that acquire overseas resources will be a favorable opportunity.

The global response to climate change will usher in a new development. The United States has not played its role in the world commensurate with the status of climate change and environmental protection, however, clean and efficient natural gas in the energy consumption structure, increasing, coal, petroleum is a large-scale replacement, will give the United States to reduce emissions, increasing the reduction discourse provide strong support. Meanwhile, the global concern shale gas revolution caused by the world energy consumption will drive clean, so as to provide opportunities to address climate change.

Sino-US relations will be presented as energy cooperation and new features. US achieve energy independence reduces both oil and gas resources to compete in the international market intensity, but also stimulated the enthusiasm of the traditional oil and gas producing country's foreign cooperation, to obtain China's overseas oil and gas resources provide an opportunity. Meanwhile, the US oil and gas exports for the oil and gas cooperation between the two countries has created opportunities, but also improve the degree of close cooperation between the two countries another way. After our country can take advantage of the advantage of fully draw on the experience of the US shale gas, shale gas exploration and 
development to promote China's breakthrough as early as possible.

\section{CONCLUSION}

All in all, Shale gas revolution is a new global political and economic factor in the field, its impact is emerging, and this effect is long-term and gradual. China needs to learn is not the focus of the historian Toynbee said artifacts level, not at the technical level, but at the institutional level: the complete protection of property rights and free competition in the market system. The United States should take advantage of the opportunity to achieve energy independence, it is possible to seek energy exports, increasing imports of foreign sources of oil and gas and resource acquisition efforts to maximize their own interests in the new round of adjustment in international relations, enhance the influence global affairs.

\section{ACKNOWLEDGEMENT}

I must express that I couldn't have finished my thesis writing without the help and support from professor Zhuang Liwei, So I would like to firstly thank him and professor Zhuang helped me and inspired me during my $\mathrm{PhD}$ study in Macau, and provided the most important advises and instructions for my topic of research. It is my great honor to be his student.

Secondly I would like to express deepest gratitude to Prof. Lin and Zhao. They are generous, expertise in academic and responsible teachers, enlightened my enthusiasm for academic research.

Most importantly and lastly, I shall never forget my beloved family. Their unconditional love and care accompanied with me through the hard and unforgotten time in Macau.

\section{REFERENCES}

[1] Harding Harry. A Fragile Relationship: The United States and China since 1972 (Learning: Theory and Practice). Washington: Brookings Institution Press, 1992.

[2] He Zhilong. Middle East History and International Relations [M], Beijing: Science Press, 2016.

[3] Henry Alfred Kissinger. On China [M], Hu Liping and other translations, Beijing: CITIC Publishing House, 2012.

[4] Huang Renwei. The History of America. Renmin Press, 2001.

[5] Jeffrey Goldberg. "The Obama Doctrine," The Atlantic (2016).

[6] Luo Xiaojun. The growth of new economic relations: 1978-2015 Sino-US economic diplomacy [M], Beijing: current affairs press, 2016.

[7] Manning Robert A. "Managing differences remains the main focus of Sino-US ties," Global Times (2015): 16.

[8] Mark Landler. "Bad Luck and Worse Manners Tarnish Obama's Asia Trip," The New York Times (2016).

[9] Martin Sieff. Shifting Superpowers: The New and Emerging Relationships between the United States, China and India. Washington: Cato Institute, 2010.

[10] Morgenthau Hans J. Politics among Nations — The Struggle for Power and Peace. Beijing: Peking University Press, 2006. 